\title{
Experimental Study for the Tenderness of Meat using Underwater Shock Waves Generation by Wire Electrical Discharges
}

\author{
Ken Shimojima ${ }^{1, a^{*}}$, Yoshikazu Higa ${ }^{1, b}$, Osamu Higa ${ }^{1, c}$, Ayumi Takemoto ${ }^{1, d}$, , \\ Hideaki Kawai ${ }^{2, e}$, Kazuyuki Hokamoto ${ }^{3, f}$ Hirofumi lyama ${ }^{4,9}$, \\ Toshiaki Watanabe ${ }^{5, \mathrm{~h}}$ and Shigeru Itoh ${ }^{6, \mathrm{i}}$ \\ ${ }^{1}$ Nat. Inst. Tech.Okinawa College of Technology,905 Henoko, Nago Okinawa905-2192, Japan \\ ${ }^{2}$ Asahi Giken, Tokura1-17-19 Toyonaka Osaka 561-0845, Japan \\ ${ }^{3}$ Kumamoto Univ.,2-39-1 Kurokami Chuo-ku Kumamoto 860-8555,Japan \\ ${ }^{4}$ Nat. Inst. Tech., Kumamoto College, Shisuya2659-2 Koushi Kumamoto 861-1102, Japan \\ ${ }^{5}$ National Fisheries Univ., 2-7-1 Nagata-Honmachi, Shimonoseki 759-6595, Japan, Japan \\ ${ }^{6}$ Inst. Shockwave Applied Technology,2070-19 Otohime Aso Kumamoto 869-2226,Japan \\ a k_shimo@okinawa-ct.ac.jp, b y.higa@okinawa-ct.ac.jp, cosamu@okinawa-ct.ac.jp, \\ dtkmt@okinawa-ct.ac.jp, ${ }^{\mathrm{e}}$ h.kawai@asahigiken-kk.com, ${ }^{\mathrm{f}}$ hokamoto@mech.kumamoto-u.ac.jp, \\ g eyama@kumamoto-nct.ac.jp, ' watanabe@fish-u.ac.jp, 'itoh_lab@okinawa-ct.ac.jp
}

Keywords: Underwater Shock Wave, Meat Softening

\begin{abstract}
High age of the population advances in the world. The consumption of meat increases. Some methods of softening of edible meat are methods such as electric energy, pressure, heating and biological. The development of the method of the tenderness that is the high efficiency which can apply to the volume of production of the meat is expected. The National Institute of Technology, Okinawa College (OkNCT) has developed a food processing machine that generates underwater shock waves through wire electrical discharge. The machine can be used for sterilization, milling, tenderness, and extraction among others. In this study, we experimentally examined the conditions for food tenderness using pork as the food material in the experiments. The relationship of the tenderness of edible meat measured with a durometer with the number of underwater shock wave generation, and the distance of the shock wave generation point from the edible meat and reflectance backing material were shown experimentally. The prototype design of the pressure vessel for the processing of the meat was shown. The possibility of designing and manufacturing of a pressure vessel according to the required tenderness was shown.
\end{abstract}

\section{Introduction}

In USA, Europe, Japan, the consumptions of edible meat increase [1-3]. The population of the elderly has been increasing in Japan. The Japanese increase rate is serious, but almost increases in all developed countries [4]. There have been many studies on the tenderness of food [5-6]. Tenderness is one of the most important sensory characteristics of meat. The conventional method of tenderness meat include pounding food materials or cutting muscle fibers with a knife or Biological method etc. [7]. It is shown that the softening of the meat using hydrodynamic shock wave. However, hydrodynamic shock wave is produced by an explosive and is unsuitable for practical use [8]. Biochemical techniques have shown the possibility of tenderness of meat [9-13].It is showed that particularly the application of the proteolytic enzymes transglutaminase and phrases, associated with nutritional, technological, and environmental improvements[14]. 
I.N.A. Ashie et al. studied on the softening of meat using an aspartic proteinase (AP) and papain on meat proteins. An improvement of 20 to 30\% was confirmed in the softening of the meat [15]. 'SLOW cooking' was shown to be effective for soft meat dishes [16]. Highly cold-shortened muscle indicated the possibility of tenderness of a meat $[17,18]$. However, it is necessary to develop mechanical devices for practical use by these new food processing method. The possibility of changing the softening of meat was shown by using high concentration of oxygen. However, processing has several days. A processing method in which the processing time is short and the design and production of a mechanical apparatus that can for practical use is realistic is effective. At OkNCT, a food processing machine that generates underwater shock waves has been developed. This device consists of a high-voltage power-supply unit for shock wave generation and a pressure vessel for processing. The effects of this processing are improvement of extractability, tenderness, and sterilization without heating [19-24]. We develop the device for processing meat using shock waves. However, the conditions of processing using shock waves and their relationships with the tenderness of meat have not been clarified. Clarification of the relationships is necessary for the design of the pressure vessel most suitable for meat processing. In this study, the relationships of the number of underwater shock wave processing and the distance of an underwater shock wave generation point from meat with the tenderness of meat were examined experimentally. The clarification of these relationships may also lead to the understanding of this mechanism of the tenderness of meat. A guideline for the design of the pressure vessel for processing meat is provided. Figure 1 shows an overview of the food processing device that generates underwater shock waves.

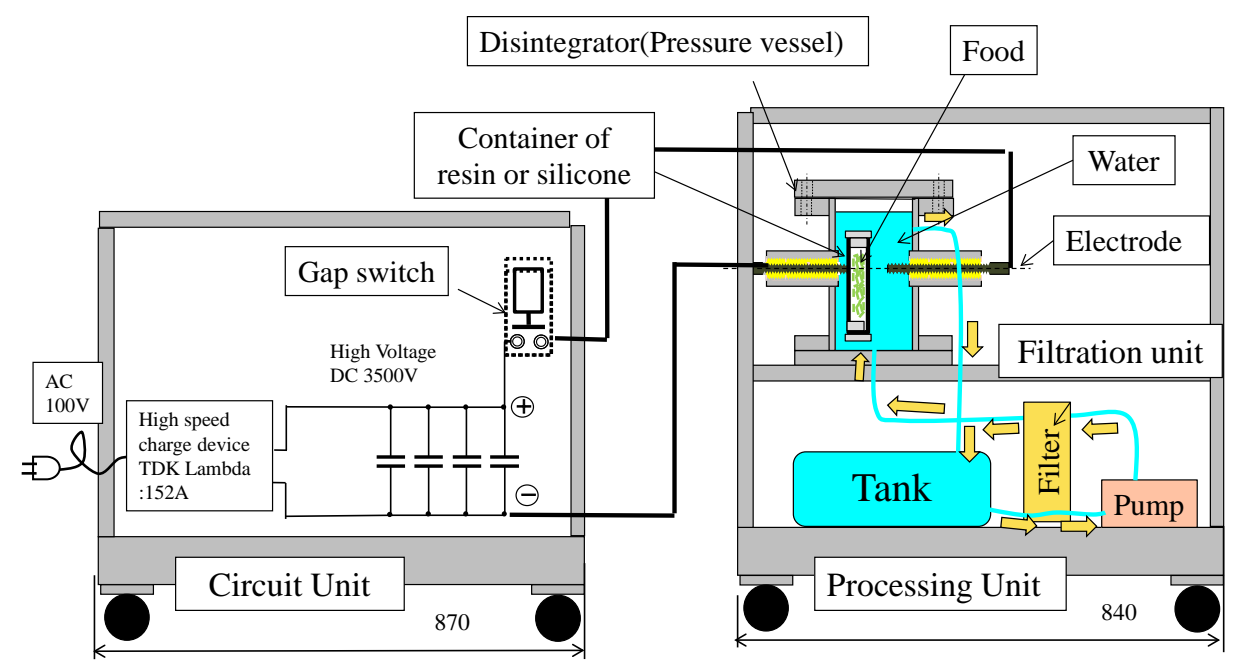

Fig.1 Figure of food processing machine for test processing

Electric energy is charged with the hi-charging device (TDK Lambda: 152A) from a switchboard $(200 \mathrm{~V}, 20 \mathrm{~A})$. The pressure vessel for food processing is filled with water. The charged electric energy is supplied to an electrode in the pressure vessel by the gap switch with the air cylinder. A thin aluminum wire is installed between electrodes, and it is evaporated by thermite reaction induced by instantaneously applied high voltage, resulting in shock wave generation. The generated shock wave propagates in the water in the pressure vessel. The food to be softened is packed with silicone or resin. The food is destroyed at the interface owing to the density difference resulting in spalling-destruction-phenomenon. The meat is processed (softened) by this phenomenon. 


\section{Experimental conditions}

2.1 Processing conditions for tenderness using the underwater shock waves

The pressure of underwater shock waves is exponentially decreases with transmission distance[25].To clarify the relationship between meat tenderness and the distance of the shock wave propagation point from the meat, meat tenderness was measured at various distances between the meat and the shock wave generation point. The effects of these waves may be unhanced by increasing the number of times shock waves are generated using this device experimentally. To clarify the relationship between the number of processing and tenderness, the tenderness of meat was measured after one to three underwater shock waves with the distance of the shockwave generation point from the meat $(135 \mathrm{~mm})$. We chose some materials of the backing material. To clarify the relationship between the backing material used and meat tenderness, meat tenderness was measured using different backing materials at various distances of the shockwave generation point from the meat $(135 \mathrm{~mm})$. Figure 2 shows a picture of the pressure vessel for experiments on tenderness.

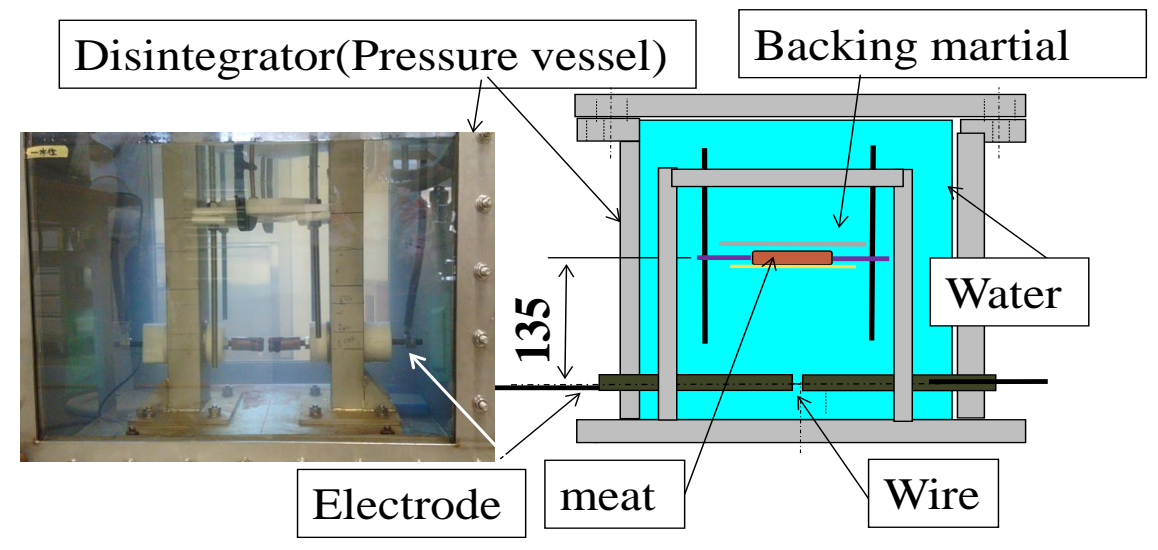

Fig.2 Picture of pressure vessel for experiment

The size of the vessel is $1 \mathrm{~m}$ cubic. This meat placed underwater is supported by a silicone sheet. The distance between the shock wave generation point and the meat is changed by screws. We prepared water (reflectance to water,0\%), wood (83.6\%), and stainless steel (92.6\%) as backing materials. The other parameters were constant. The charge voltage was 3.5KV, the condenser capacity was $800 \mu \mathrm{F}$ (This is connected by four parallel). The materials of thin line is aluminum. The diameter of the thin line was $1 \mathrm{~mm}$, the distance of the thin line at each electrodes was $8 \mathrm{~mm}$.

\subsection{Method of measurement of tenderness}

We chose pork, as the material for studying the tenderness effect on edible meat. Because tenderness differs depends on part of meat, we processed meat after cutting the red meat part. Figure 3 shows the measurement points on the meat. The red meat of pork shown in the figure was $10 \mathrm{~cm}$ in width, $12 \mathrm{~cm}$ in height, and $1 \mathrm{~cm}$ in thickness. The measurement points were indicated by red food dye. The measurement points were located as follows: one point at the center of the meat, one each above and below the center point, two points each on the right and left sides of the center point. The distance between points wad $1 \mathrm{~cm}$. The tenderness of each point was measured after processing with shock waves. 


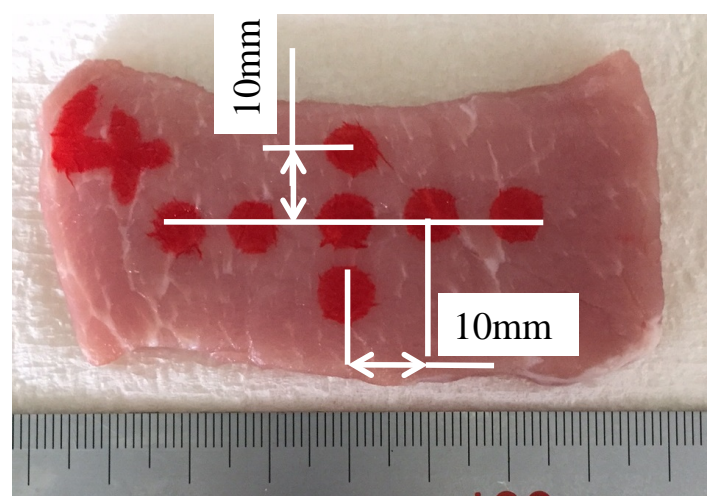

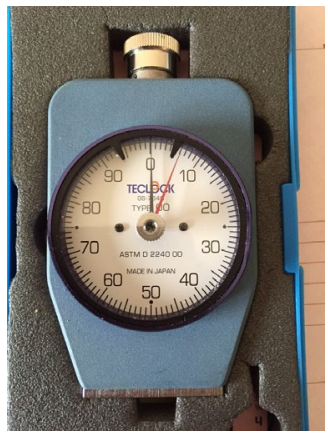

Maker: TecLock Co.,

Type: $\mathrm{OO}$

Load value of spring

:203-1111mN

the shape of push needle

:hemispherical

Radius of needle: $1.19 \mathrm{~mm}$

Measurement duration time :1 s

Fig. 3 Measuring points of meat (pork)

\subsection{Evaluation of tenderness}

For the evaluation of the tenderness of meat, we mesured the tenderness of meat using a durometer. Figure 4 shows the specifications of the durometer. This measuring instrument was made in TecLock Co., the type is OO, the load value of the spring is $203-1111 \mathrm{mN}$, the shape of the push needle is a hemispherical (Radius, $1.19 \mathrm{~mm}$ ), the contact time between the durometer and the meat is approximately $1 \mathrm{~s}$. This measurement is in accordance with "ASTM D 2240"[26]. We measured the meat five times at each measurement point and calculated the mean.

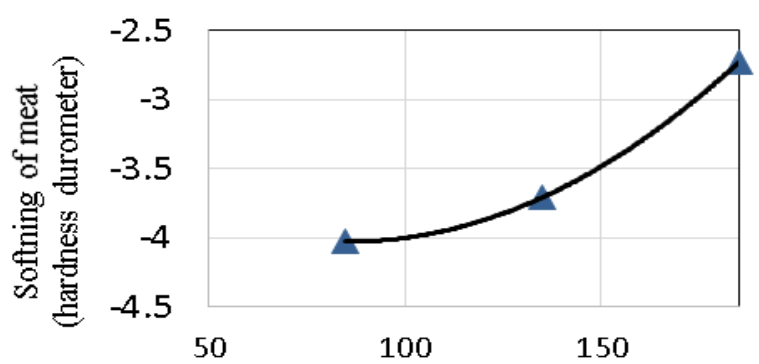

Distance between meat and generation point (mm)

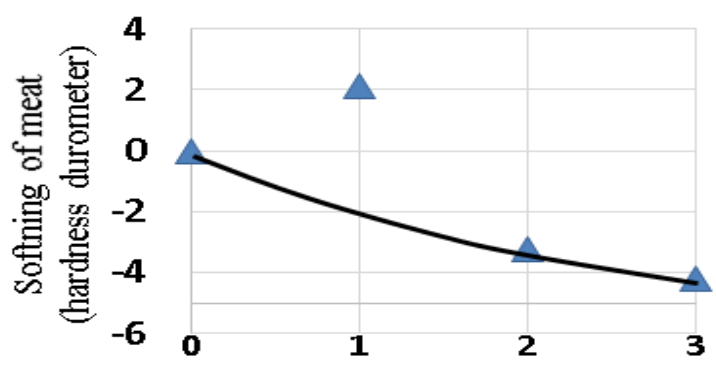

Number of times of shock wave

Fig.5 Relationship between distance and hardness Fig.6 Relationship between number of times of shock wave generation and hardness

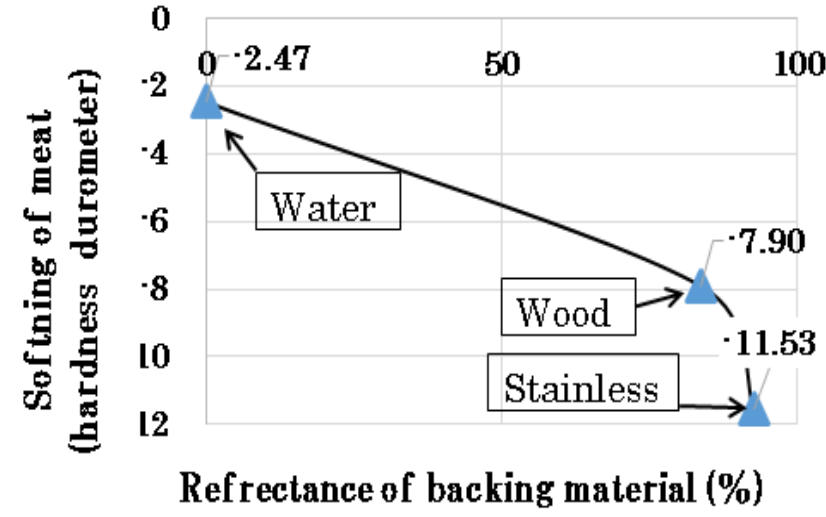

Fig.7 Relationship between backing material and hardness

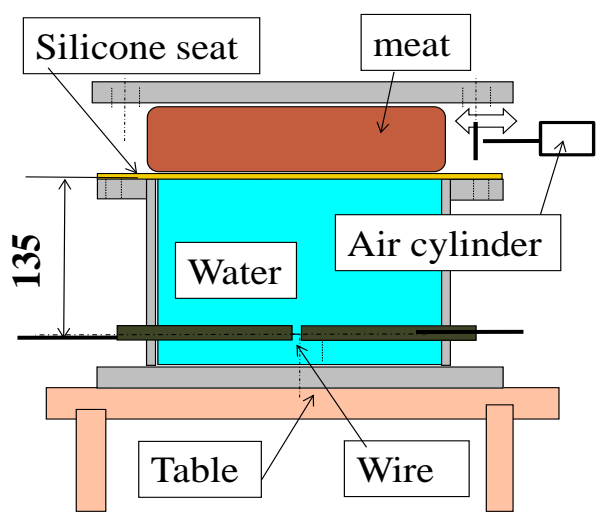

Fig.8 Picture of comcept design of pressure vessel 


\section{Experiment result and discussion}

Figure 5 shows the relationship between the distance of the shock wave generation point from the meat (Horizontal axis) and hardness (tenderness) of meat (Vertical axis). As the distance dereases, it is obvious that the meat became tender.Figure 6 shows the relationship between number of times shock waves were generated (horizontal axis) and the hardness (tenderness) of meat (vertical axis). A negative hardness value is indicated that the meat is softened. After the third shock wave generation, meat is clearly softened by about 1.8 fold. The meat was hard after one time shock wavecompared with the other number of times of processing. The otherexperimental processing (extraction and flour milling) in this study showd negative effect after one time shock wave processing[27,28]. It will be necessary clarify to the reason why the meat became hard after one-time shock wave processing, as shown by observation undar a microscope. Figure 7 shows the relationship between the reflectance of the backing material to water and tenderness.

The acoustic impedance that reflectance is decided on is calculated by the multiplication of density of the meat and the speed of sound. A different reflection expansion wave occurs by materials of the back materials, and it is assumed that a change occurred in the hardness of the meat.The effect of the backing material on tenderness was found to be larger than those of the number of times of shock wave generation and the distance between the meat and the shock wave generation point. Figure 8 shows a prototype design of the pressure vessel for processing meat using underwater shock waves. We can manufacture the pressure vessel for meat tenderness by setting the distance between the meat and the shock wave generation point, the backing material, and the transport speed of meat calculated from charging time and the numbr of times of shock wave generation according to the desired hardness (tenderness) measured using a durometer.

\section{References}

[1] Kevin Uhrmacher / NPR,National Agricultural Statistics Service,2016

[2] GLOBAL POULTRY TRENDS 2014: Poultry Meat Uptake in Europe Sure to Slow,15 October 2014

[3] S.Stoll-Kleemanna,T.O'Riordanb,The Sustainability Challenges of Our Meat and Dairy

Diets,vo.57,Num.3,EnvironmEnt,2015

[4] World population prospects, the 2015 revision, United nations, Department of economic and social affairs

[5] Hiroshi Sekiguchi, Yukio Machida and Sadao Omata , Evaluation of the Hardness of Foods measured by

The New Tactile Sensor for Detecting Hardness, Jpn Pediatr Soc., Vol.34,No.4,1,99-109,(1996)

[6] Takashi OKAZAKI,Kanichi SUZUKI,Shizuhiko MAESHIGE and Kiyoshi KUBOTA, Simulation of

Potato Tenderness during Non-isothermal and Isothermal Processes, Nippon Shokuhin Kogyo Gakkaishi

Vol.39, No.4, 295 301 (1992), https://doi.org/10.3136/nskkk1962.39.295

[7] M B Solomon, J B Long and J S Eastridge,The hydrodyne: a new process to improve beef tenderness, Vol.75 No.6,Journal of Animal Science,p.1534-1537, https://doi.org/10.2527/1997.7561534x

[8] Tomas Bolumar, Mathias Enneking, Stefan Toepfl,Volker Heinz,New developments in shockwave technology intended for meat tenderization: Opportunities and challenges,Meat Science 95 (2013) 931-93, https://doi.org/10.1016/j.meatsci.2013.04.039

[9] Donald de Fremery,Morris F. Pool, Biochemistry of Chicken Muscle as Related to Rigor Mortis and Tenderization,Journal of Food Science,Volume 25, Issue 1,January 1960,Pages 73-87, https://doi.org/10.1111/j.1365-2621.1960.tb17938.x

[10] I.H. Hwanga, C.E. Devineb, D.L. Hopkinsc, The biochemical and physical effects of electrical stimulation on beef and sheep meat tenderness, Volume 65, Issue 2, October 2003, Pages 677-691, https://doi.org/10.1016/s0309-1740(02)00271-1

[11] Huff Lonergan E1, Zhang W, Lonergan SM., Biochemistry of postmortem muscle - lessons on mechanisms of meat tenderization,Meat Science,Volume86, Number 1,2010, pages 184-95, https://doi.org/10.1016/j.meatsci.2010.05.004 
[12] Koohmaraie M.Biochemical factors regulating the toughening and tenderization processes of meat, Meat Science,Volume 43, Supplement 1, 1996, Pages 193-201, https://doi.org/10.1016/0309-1740(96)00065-4 [13] Huff Lonergan E1, Zhang W, Lonergan SM.,Biochemistry of postmortem muscle - lessons on mechanisms of meat tenderization,Meat Science,Volume 86, Issue 1, September 2010, Pages 184-195, https://doi.org/10.1016/j.meatsci.2010.05.004

[14] Anne y Castro Marques, Mário Roberto Maróstica Jr., and Gláucia Maria Pastore, Some Nutritional, Technological and Environmental Advances in the Use of Enzymes in Meat Products, SAGE-Hindawi Access to Research,Enzyme Research,Volume 2010, Article ID 480923, https://doi.org/10.4061/2010/480923

[15] I.N.A. Ashie,T.L. Sorensen,P.M. Nielsen, Effects of Papain and a Microbial Enzyme on Meat Proteins and Beef Tenderness, Journal of Food Science,Volume 67, Issue 6,August 2002,Pages 2138-2142, https://doi.org/10.1111/j.1365-2621.2002.tb09516.x

[16] D. A. King,M. E. Dikeman,T. L. Wheeler,C.L.Kastner and M. Koohmaraie, Chilling and cooking rate effects on some myofibrillar determinants of tenderness of beef, Journal of Animal Science,Volume 81,Number 6,pp.1473-1481, https://doi.org/10.2527/2003.8161473x

[17] B. B. MaARSH, N. G. LEET,M. R. DICKSON, The ultrastructure and tenderness of highly coldshortened muscle, Journal of Food Science and Technology,Volume 9,Issue 2,June 1974,Pages 141-147, https://doi.org/10.1111/j.1365-2621.1974.tb01757.x

[18] B. B. MARSH,N. G. LEET, Studies in Meat Tenderness. III. The Effects of Cold Shortening on Tenderness, Journal of Food Science and TechnologyVolume 31, Issue 3,May 1966,Pages 450-459, https://doi.org/10.1111/j.1365-2621.1966.tb00520.x

[19] S. Itoh, K. Hokamoto, Explosion, Shock Wave and Hypervelocity Phenomena in Materials II, Materials Science Forum (Volume 566), November 2007,pp. 361-372, https://doi.org/10.4028/0-87849-465-0.361 [20] Yoshikazu HIGA, Hirofumi IYAMA, Ken SHIMOJIMA, Atsushi YASUDA, Osamu HIGA, Ayumi TAKEMOTO and Shigeru ITOH, Computational Simulation for Evaluation of Food Tenderness Treatment Vessel using Underwater Shockwave, ASME 2016 Pressure Vessels \& Piping Division Conference PVP2016 PVP2016-63530 Aug, 2016, https://doi.org/10.1115/pvp2016-63530

[21] Ken SHIMOJIMA, Yoshikazu HIGA, Osamu HIGA, Ayumi TAKEMOTO, Hirofumi IYAMA, Atsushi YASUDA, Toshiaki WATANABE and Shigeru ITOH, Visualization of Shock Wave Propagation Behavior of the General-Purpose Batch Processing for Pressure Vessel by Numerical Simulation, ASME 2016 Pressure Vessels \& Piping Division Conference PVP2016 PVP2016-63510 ,Aug,2016, https://doi.org/10.1115/pvp2016-63510

[22] Ken Shimojima,Yoshikazu Higa,Osamu Higa,Atsushi Yasuda,Ayumi Takemoto,Shigeru Itoh,Hirofumi Iyama,Toshiaki Watanabe,Development of Prototype Machine for Food Processing by Underwater Shock Wave, The 2nd International Conference on Engineering Science and Innovative(ESIT 2016), Phuket, Thailand, April 21 - 23 (2016), PaperID:No.12,PP.360-365, https://doi.org/10.1115/pvp2016-63530 [23] Yoshikazu HIGA,Hirofumi IYAMA,Ken SHIMOJIMA,Atsushi YASUDA,Osamu HIGA, Ayumi TAKEMOTO,Shigeru ITOH,Computational Simulation of Shock Wave Propagation Characteristics in Foods, The 2nd International Conference on Engineering Science and Innovative(ESIT 2016), Phuket, Thailand, April 21 - 23 (2016),PaperID:No.13,PP.366-371, https://doi.org/10.1109/esit.2018.8665029 [24] Higa, K. Higa, H. Maehara, S. Tanaka, K. Shimojima, A. Takemoto, K. Hokamoto and S. Itoh; EFFECTS OF IMPROVING CURRENT CHARACTERISTICS OF SPARK DISCHARGE ON UNDERWATER SHOCK WAVES, The International Journal of Multiphysics, Vol. 8, No. 2, pp.245-252, 2014, https://doi.org/10.1260/1750-9548.8.2.245

[25] Ben-Dor, Gabi,shock Wave Reflection PhenomenaSpringer,Springer

[26] Standard Test Method for Rubber Property—Durometer Hardness, Active Standard ASTM D2240-15

[27] Ken SHIMOJIMA, Osamu HIGA, Yoshikazu HIGA, Ayumi TAKEMOTO, Hirofumi IYAMA, Atsushi YASUDA, Toshiaki WATANABE and Shigeru ITOH,Production of Rice Powder Milling Flour Device and Characterization by Numerical Simulation,ASME 2016 Pressure Vessels \& Piping Division Conference PVP2016 PVP2016-63588 Aug.2016, https://doi.org/10.1115/pvp2016-63588

[28] K. Shimojima, A. Takemoto, M. Vesenjak, Y. Higa, Z. Ren, S. Itoh,The effect of improving the oil extraction of Slovenia production seed by underwater shock wave,MULTIPHYSICS 2015,10-11 Dec 2015, London, United Kingdom,P.9 